\title{
Comparison Between the Effect of Femtosecond Laser in situ Keratomileusis (FS-LASIK) and Femtosecond Small Incision Lenticule Extraction (FS-SMILE) on the Corneal Endothelium
}

This article was published in the following Dove Press journal: Clinical Ophthalmology

\author{
Yasmine Maher Shaaban (iD) 1,2 \\ Tamer Abdel Fattah Badran ${ }^{1,2}$ \\ 'Department of Ophthalmology, Faculty \\ of Medicine, Ain Shams University, Cairo \\ I I566, Egypt; ${ }^{2}$ The Eye Subspecialty \\ Center (ESC), Cairo II 402, Egypt
}

Purpose: To compare the effect of FS-LASIK and FS-SMILE on the corneal endothelial cell density (ECD) and morphology.

Patients and Methods: This is a prospective, cohort observational study that included 80 eyes of two equal groups of patients. Forty eyes were subjected to the FS-LASIK, and 40 eyes were subjected to the FS-SMILE. In both groups, patients, age ranged between 19 and 37 years with myopia ranges from -0.75 to -9.00 diopters (D) and astigmatism up to $-3.00 \mathrm{D}$. The ECD, coefficient of variation (CV), and hexagonality (HEX) in both groups were compared over six months. Specular microscopy was used to evaluate the corneal endothelium throughout the study.

Results: In both groups, ECD showed a statistically significant decrease while CV showed a statistically significant increase in the first month postoperatively. The FS-SMILE had more impact on both ECD and CV until the third and six months, respectively. Hexagonality showed a significant decrease in both groups throughout the whole study. In both groups, no vision-threatening complications occurred, and no eyes developed any corneal complications over a six-month follow-up period.

Conclusion: Although the ECD, CV, HEX are statistically affected in both FS-LASIK and FS-SMILE groups, both procedures have no significant adverse effects on the ECD and morphology. The impact of the FS-SMILE group may be due to the deeper penetration of the femto laser in the corneal tissue compared to the FS-LASIK. The closer the femto laser to the endothelium, the more exposure to the shock waves and heat energy, although minimal but it can cause collateral damage to this layer. The effects of FS-SMILE surgery on corneal endothelial cells and morphology need further investigations.

Keywords: cornea, endothelium, FS-LASIK, FS-SMILE

\section{Introduction}

Refractive surgery is one of the commonest surgeries done worldwide. The most commonly used techniques to correct refractive errors include LASIK (laser in situ keratomileusis), femtosecond laser in situ keratomileusis (FS-LASIK), and the FSsmall incision lenticule extraction (FS-SMILE). Laser in situ keratomileusis (LASIK) had been described in 1990 and has become a widely used procedure to correct myopia. ${ }^{1}$ It combines the creation of a corneal flap using a microkeratome and ablation of the underlying corneal stroma using an excimer laser. Later on, FS-LASIK was
Correspondence: Yasmine Maher Shaaban Ophthalmology Department, Faculty of Medicine, Ain Shams University, Abbassyia, Cairo II566, Egypt Email yasminemaher0@gmail.com 
introduced $^{2}$ with no microkeratome to use but pulses of short duration (femtosecond laser) are used to create a thin-hinged corneal flap. An excimer laser is used for stromal bed ablation and the flap is reposited back. Femto lasers are infrared light and this is the reason that it does penetrate in transparent tissues, in contrast with excimer, which is a UV light, that can not penetrate even in transparent tissues. In Small Incision Lenticule Extraction (SMILE), the procedure is performed entirely through a small incision rather than by creating and lifting a hinged flap. The risk of flap-related complications is reduced, the procedure is done without the use of an excimer laser, and the refractive error is corrected by removing a lenticule. ${ }^{3}$ The SMILE procedure is now becoming popular following the results of the first prospective trials. ${ }^{4-6}$ SMILE may bring some advantages over LASIK. These advantages are due to the minimally invasive cap incision nature of the procedure which results in maximal maintenance of the structural integrity, anterior corneal innervation, and induces less postoperative dry eye. ${ }^{7}$ Despite these advantages, the Femto-SMILE deeper corneal penetration and the closer of the shock waves to the corneal endothelial cells may increase the risk of endothelial affection as compared to the FemtoLASIK. Short and long- term effects of Femto-SMILE surgery on corneal endothelial cells and its morphology need further investigation. The objective of this research is to compare the effect of Femto-LASIK and Femto-SMILE Laser eye surgeries on the corneal endothelial cells over 6 months.

\section{Patients and Methods}

This was a prospective, cohort observational study that was performed in the Refractive Surgery Unit in The Eye Subspecialty Center (ESC), Heliopolis,11402, Cairo, Egypt. All procedures in this study adhered to the Declaration of Helsinki (2008) Ethical Principles for Medical Research Involving Human Subjects and approved by the Eye Subspecialty Center (ESC) ethics committee. Written informed consent was obtained from all the candidates. The study was performed in the period between July 2019 through March 2020.

The inclusion criteria were 40 healthy adults (80 eyes), age ranged between 19 and 37 years with myopia from -0.75 to -9.00 diopters (D) and astigmatism up to -3.00 diopters (D). The refractive errors have not undergone any changes during the year preceding the procedure.

The exclusion criteria were diabetes mellitus, glaucoma, systemic collagen or immune disease, uncontrolled systemic or ocular diseases, severe dry eyes, thin corneas, corneal scarring, keratoconus, viral eye infections, unstable refraction, history of tear replacement therapy, regular contact lens wear during the previous year, and those patients who used drugs that affected tear secretion and tear film stability such as corticosteroids and antiglaucoma drugs. Patients with residual stromal bed $\leq 250$ microns were also excluded. Pregnancy and breastfeeding cases were postponed.

The pre-surgical assessment included refraction to check stability, Pentacam to measure the central corneal thickness, topography, keratometry, and the size of the pupil. Fundus examination was done for all candidates, and cycloplegic refraction was performed in young myopes. Contact lens wearers stopped using their lenses for two weeks before the pre-operative assessment to get the most accurate topography and keratometry measurements. In this study, there were only two patients in each group who used to wear contact lenses but not daily for less than a year. Since postoperative dry eye can occur with any corneal refractive surgery procedure, slit lamp tear film assessment was done to identify patients who had dry eyes pre-operatively. Patients were selected for each procedure according to the degree of myopia, and astigmatism, preoperative topography, and pachymetry. In patients with high degrees of myopia and small degrees of astigmatism, patients with critical pachymetry, patients with dry eyes in preoperative assessment, and those who were liable to trauma like athletics, FS-SMILE was preferred. Femto-SMILE preserves the corneal biomechanics as compared to flap creation in Femto-LASIK and produces less dryness postoperatively. Those with higher degrees of astigmatism were preferred to have FemtoLASIK to take advantage of the eye-tracking system and the iris registration system and to avoid the effect of cyclotorsion during correction of astigmatism. Irritable and uncooperative patients were also preferred to have Femto-LASIK due to the less suction time and the highpressure system as compared to Femto-SMILE, thus decreasing the incidence of suction loss. Before the procedure, the eye was anesthetized with a topical anesthetic (Benoxinate hydrochloride 0.4\%). During the procedure, the anesthetized eyes were thoroughly disinfected and covered with a sterile dressing. The eyelashes were moved aside, and the eyes once again anesthetized using the (Benoxinate hydrochloride $0.4 \%$ ). An eyelid speculum was put into place. Both eyes of each patient had the same surgery. 


\section{Surgical Methods}

In case of FS-Lasik procedure, the (Refractive Suite from Allegretto wave light for Femto LASIK; Alcon Laboratories, Inc., Fort Worth, TX, USA) was used. This suite consists of two laser platforms (a femtosecond laser for flap creation and an excimer laser for stromal bed ablation). Femtolaser works using the principle of photo disruption: using infrared laser energy, the surgeon creates a pattern of tiny, overlapping spaces immediately under the surface of the cornea. The laser operates at extremely high speeds. These highly precise laser impulses split the corneal tissue at a molecular level with no heat creation or touching the nearby tissue. As the laser moves up and down across the eye, a complete corneal flap is formed. After the flap has been created, the surgeon lifts it with a spatula. The excimer laser is then used to shave away thin slices of the cornea correcting the refractive errors. Finally, the surgeon replaces the flap.

In FS- SMILE, the femtosecond laser scanning was performed, and the corneal refractive lenticule was performed through the micro-incision using (ReLExfemtosmile; Carl Zeiss Meditec AG, Jena, Germany). The VisuMax FSL ((Carl Zeiss Meditec, Jena, Germany) is used for refractive lenticule extraction without the use of an excimer laser or a microkeratome). This procedure was done by passing a dissector through a small $2-3 \mathrm{~mm}$ incision to separate the lenticular interfaces and remove the lenticule, without the need to perform a flap. The cap was put back.

Specular microscopy (EM-3000 CBD/Tomey, AZ, Phoenix, USA), a fully automated device, was used to evaluate the corneal endothelium before surgery and throughout the study. In this procedure, the patient fixes his chin, each eye was examined separately, no eye drops were needed, as it's a non-contact procedure, and the patient was asked to blink before capture. Fifteen shots were taken in series and the best image was automatically selected by the device software. Photos were taken at 7 points; center and 6 peripheral points at 2, 4, 6, 8, 10, 12 o'clock position on a $6 \mathrm{~mm}$ arc, then the software automatically analyzed the data. All the measurements were taken by the same examiner in all sessions.

Postoperative management: Patients in both groups received antibiotic eye drops moxifloxacin hydrochloride ophthalmic solution $0.5 \%$ four times daily for a week, and prednisolone acetate ophthalmic solution $1 \%$ four times daily for a week, then it was tapered over the following month. Carboxymethylcellulose sodium eye drops were given four times daily for two months after the operation. The postoperative follow-up visits were scheduled to be after one day, one week, one, three, and six months. All patients were instructed to stop the eye drops 3 hours before the examination.

\section{Statistics}

Mean and the standard deviation were used to present quantitative data. Independent two samples mean was used to test the equality of means between the two treatment groups. Proportions were used to present qualitative data with the Chi-square test as a test of significance.

Data of ECD, CV, and HEX from the preoperative level throughout the study were analyzed using repeated measure ANOVA with between-group factor (the type of operation). The full model was used, and when the interaction term proved statistically significant, simple effect rather than main effects were tested using post hoc Bonferroni correction. A p-value $\leq 0.05$ was considered statistically significant. The Statistical Package for the Social Sciences (SPSS version 23.0; for windows, IBM Corporation 2015 release, Armonk, NY, USA) was used in data management and statistical analysis.

\section{Results}

The age in the FS-LASIK group was $29.28 \pm 5.25$ years and in the FS-SMILE group was $28.3 \pm 4.97$ years with no statistically significant difference $(\mathrm{p}=0.396)$. Eighteen eyes in the FS-LASIK group were males (45\%) compared to 16 eyes in the FS-SMILE group (40\%) and twenty-two eyes in the FS-LASIK group were females (55\%) compared to 24 eyes in the FS-SMILE group (60\%), which was statistically insignificant (Chi-square $=0.205, \mathrm{p}=0.651$ ). Table 1 shows the demographic and postoperative data concerning the refractive status of all the patients.

Endothelial cell density (ECD) shows a statistically significant decrease in both FS-LASIK and FS-SMILE in the first month postoperatively. FS-SMILE shows a significant decrease until the third month postoperatively (Tables 2,5,6 and Figure 1).

The Coefficient of variation (CV) shows a significant increase in both FS-LASIK and FS-SMILE groups in the first month postoperatively. FS-SMILE shows a significant increase in the $\mathrm{CV}$ in the six months postoperatively (Tables 3,5,7 and Figure 2).

Hexagonality (HEX) shows a significant decrease in both FS-LASIK and FS-SMILE cases throughout the whole study. FS-SMILE cases show a more significant 
Table I The Demographic and Postoperative Data Concerning the Refractive Status of the Patients

\begin{tabular}{|l|l|l|}
\hline & $\begin{array}{l}\text { FS-LASIK } \\
\mathbf{( N = 4 0 )}\end{array}$ & $\begin{array}{l}\text { FS-SMILE } \\
\mathbf{( N = 4 0 )}\end{array}$ \\
\hline Age & $29.28 \pm 5.25$ & $28.3 \pm 4.97$ \\
Preoperative refraction sphere & $-4.06 \pm 1.94$ & $-5.18 \pm 1.86$ \\
Postoperative refraction sphere & $0.01 \pm 0.29$ & $-0.08 \pm 0.3$ \\
Preoperative refraction cylinder & $-1.18 \pm 0.92$ & $-2.66 \pm 2.75$ \\
Postoperative refraction & $-0.18 \pm 0.17$ & $-0.16 \pm 0.22$ \\
cylinder & & \\
\hline
\end{tabular}

Table 2 Mean and SD of the ECD in Both FS-LASIK and FSSMILE Groups Preoperatively and Postoperatively Through the Follow-Up Period

\begin{tabular}{|l|l|l|}
\hline ECD & $\begin{array}{l}\text { FS-LASIK (N=40) } \\
\text { Mean } \pm \text { SD }\end{array}$ & $\begin{array}{l}\text { FS-SMILE (N=40) } \\
\text { Mean } \pm \text { SD }\end{array}$ \\
\hline Preoperative & $2946.50 \pm 151.28$ & $3037.88 \pm 160.81$ \\
Postoperative one month & $2909.13 \pm 147.43$ & $2916.13 \pm 180.52$ \\
Postoperative three months & $2903.63 \pm 150.30$ & $2904.38 \pm 176.43$ \\
Postoperative six months & $2900.53 \pm 150.47$ & $2912.75 \pm 169.60$ \\
\hline
\end{tabular}

Notes: The main effect of time is statistically significant (Greenhouse-Geisser $F=154.823, p<0.001)$. The main effect of the type of operation is statistically insignificant $(F=0.612, p=0.436)$. The interaction term is statistically significant $(F=39.158, p<0.001)$. Because the interaction term is statistically significant, the simple effects were reported instead.

Abbreviations: SD, standard deviation; ECD, endothelial cell density; FS-LASIK, femtosecond laser in situ keratomileusis; FS-SMILE, femtosecond small incision lenticular extraction.

decrease in hexagonality specifically in the first month (Tables 4,5,8 and Figure 3).

In both groups, no vision-threatening complications occurred during the six-month follow-up period. No eyes developed corneal edema or any other corneal complications.

\section{Discussion}

The effectiveness, safety, and stability of using laserassisted in situ keratomileusis (LASIK) for the correction of refractive errors have been well established but with the development and advances of the femtosecond laser and intrastromal techniques (SMILE), there was no requirement for flap lifting of LASIK.

The small incision lenticule extraction (SMILE) technique has been suggested to offer some biomechanical advantage over laser-assisted in situ keratomileusis (FS-LASIK) with excellent postoperative outcomes, fast recovery of postoperative dry eye and quicker reinnervation of corneal nerves. ${ }^{\mathbf{8}}$ Avoiding a flap lifting of a LASIK and preserving the strong ${ }^{9}$ anterior collagenous stromal lamellae of the cornea may offer a biomechanical advantage for SMILE. ${ }^{10}$

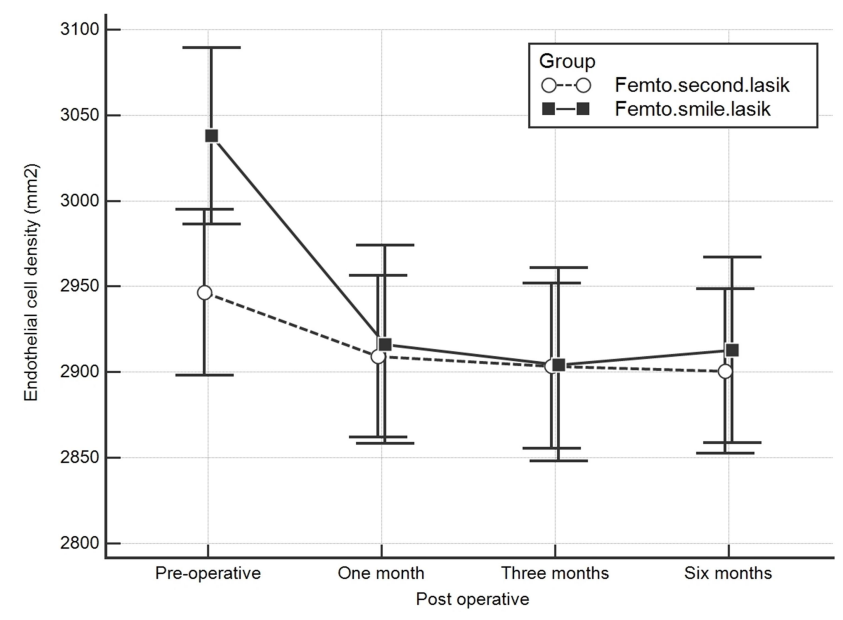

Figure I Showing the endothelial cell density in both treatment modalities over the different points of follow-up.

Abbreviations: FS-LASIK, femtosecond laser in situ keratomileusis; FS-SMILE, femtosecond small incision lenticular extraction.

Although both FS-LASIK and FS-SMILE procedures are used to treat myopia with or without astigmatism, and both are comparable in results, Femto SMILE features such as the deeper penetration of the corneal tissue, the closer shock waves, and the heat energy delivered to corneal endothelial cells may be considered as risk factors that may affect corneal endothelial cell count and morphology.

Previous studies concerning the effect of FS-LASIK, and FS-SMILE on the corneal endothelial cells reported no statistically significant differences ${ }^{11,12,14}$ and no significant impairment of the corneal endothelium in short and longterm follow-up periods of the studies ${ }^{4-6,11-19}$ In our study, although we reported statistically significant changes in ECD, CV, and HEX in both FS-LASIK and FS-SMILE groups, with more affection in the FS-SMILE group, the

Table 3 Mean and SD of the CV in Both FS-LASIK and FS-SMILE Groups Preoperatively and Postoperatively Through the FollowUp Period

\begin{tabular}{|l|l|l|}
\hline CV & $\begin{array}{l}\text { FS-LASIK (N=40) } \\
\text { Mean } \pm \text { SD }\end{array}$ & $\begin{array}{l}\text { FS-SMILE (N=40) } \\
\text { Mean } \pm \text { SD }\end{array}$ \\
\hline Preoperative & $29.48 \pm 2.87$ & $28.38 \pm 2.24$ \\
Postoperative one month & $31.30 \pm 2.98$ & $32.48 \pm 2.62$ \\
Postoperative three months & $31.55 \pm 3.29$ & $32.93 \pm 2.43$ \\
Postoperative six months & $31.75 \pm 3.27$ & $33.03 \pm 2.47$ \\
\hline
\end{tabular}

Notes: The main effect of time is statistically significant (Greenhouse-Geisser $F=278.360, p<0.001)$. The main effect of the type of operation is statistically insignificant $(F=1.282, P=0.261)$. The interaction term is statistically significant $(F=36.82 \mathrm{I}, \mathrm{P}<0.00 \mathrm{I})$. Because the interaction term is statistically significant, the simple effects were reported instead.

Abbreviations: SD, standard deviation; CV, coefficient of variation of the cell size; FS-LASIK, femtosecond laser in situ keratomileusis; FS-SMILE, femtosecond small incision lenticular extraction. 


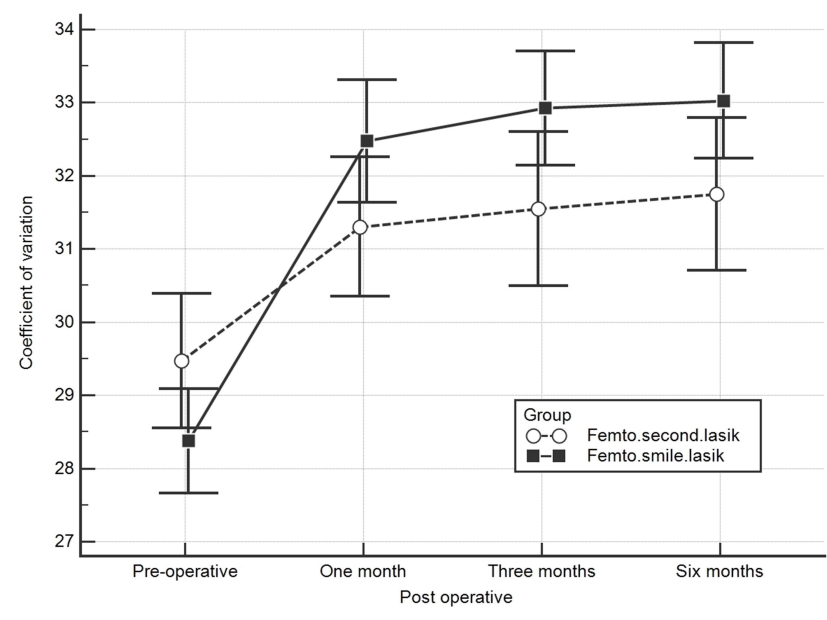

Figure 2 Showing the coefficient of variation of the cell size in both treatment modalities over the different points of follow-up.

Abbreviations: FS-LASIK, femtosecond laser in situ keratomileusis; FS-SMILE, femtosecond small incision lenticular extraction.

values, and percentage of changes in both groups appeared to induce no significant harm to the corneal endothelial cells or its morphology (Tables 2-5).

In the FS-LASIK group, we had preoperative ECD of $2946.5 \pm 151.28 / \mathrm{mm}^{2}$, which turned to be $2900.53 \pm$ $150.47 / \mathrm{mm}^{2}$ six months postoperatively $(-1,55 \%$ decrease) (Tables 2 and 5). In the FS-SMILE group, we had preoperative ECD of $3037.88 \pm 160.81 / \mathrm{mm}^{2}$, which turned to be $2912.75 \pm 169.60 / \mathrm{mm}^{2}$ six months postoperatively ( $-4,11 \%$ decrease) (Tables 2 and 5$)$. The percentage of increase in CV1, CV3, and, CV6 postoperatively in the FS-LASIK group was less than in the FS-SMILE group (Tables 3 and 5). The percentage of decrease in HEX1, EX3, and, HEX6 in the FS-LASIK group was less than in the FS-SMILE group (Tables 4 and 5).

Table 4 Mean and SD of the HEX in Both FS-LASIK and FSSMILE Groups Preoperatively and Postoperatively Through the Follow-Up Period

\begin{tabular}{|l|l|l|}
\hline HEX & $\begin{array}{l}\text { FS-LASIK (N= 40) } \\
\text { Mean } \pm \text { SD }\end{array}$ & $\begin{array}{l}\text { FS-SMILE (N=40) } \\
\text { Mean } \pm \text { SD }\end{array}$ \\
\hline Preoperative & $60.08 \pm 2.93$ & $61.68 \pm 2.60$ \\
Postoperative one month & $57.78 \pm 3.42$ & $57.33 \pm 2.63$ \\
Postoperative three months & $57.28 \pm 3.37$ & $56.83 \pm 2.61$ \\
Postoperative six months & $57.05 \pm 3.20$ & $56.70 \pm 2.53$ \\
\hline
\end{tabular}

Notes: The main effect of time is statistically significant (Greenhouse-Geisser $\mathrm{F}=591.347, \mathrm{P}<0.00 \mathrm{I})$. The main effect of the type of operation is statistically insignificant $(F=0.019, P=0.892)$. The interaction term is statistically significant $(\mathrm{F}=42.6 \mathrm{I}, \mathrm{p}<0.00 \mathrm{I})$. Because the interaction term is statistically significant, the simple effects were reported instead.

Abbreviations: SD, standard deviation; HEX, hexagonality of the endothelial cells; FS-LASIK, femtosecond laser in situ keratomileusis; FS-SMILE, femtosecond small incision lenticular extraction.
Table 5 Percent of Change of the ECD, CV, and HEX from Baseline Value Through the Follow-Up Period

\begin{tabular}{|l|l|l|l|l|}
\hline & \multicolumn{2}{l|}{ FS-LASIK } & \multicolumn{2}{l|}{ FS-SMILE } \\
\hline & Mean & SD & Mean & SD \\
\hline ECDI & -1.26 & 1.01 & -4.04 & 2.02 \\
ECD3 & -1.45 & 1.24 & -4.42 & 2.00 \\
ECD6 & -1.55 & 1.23 & -4.11 & 2.77 \\
CVI & 6.34 & 5.18 & 14.64 & 7.22 \\
CV3 & 7.12 & 5.56 & 16.24 & 6.54 \\
CV6 & 7.83 & 6.11 & 16.60 & 6.85 \\
HEXI & -3.86 & 2.20 & -7.04 & 2.17 \\
HEX3 & -4.69 & 2.11 & -7.86 & 2.02 \\
HEX6 & -5.05 & 1.99 & -8.05 & 2.00 \\
\hline
\end{tabular}

Abbreviation: SD, standard deviation; $\mathrm{ECD}$, endothelial corneal density; CV, coefficient of variation; HEX, hexagonality of the endothelial cells; FS-LASIK, femtosecond laser in situ keratomileusis; FS-SMILE, femtosecond small incision lenticular extraction.

Table 6 P-value in a Pairwise Comparison of the ECD Between Time Points for Each Treatment Modality

\begin{tabular}{|c|c|c|}
\hline $\begin{array}{l}\text { A Pairwise Comparison at Different } \\
\text { Points of Time }\end{array}$ & $\begin{array}{l}\text { FS-LASIK } \\
(\mathrm{N}=40) \\
\text { P-value }\end{array}$ & $\begin{array}{l}\text { FS-SMILE } \\
(\mathrm{N}=40) \\
\text { P-value }\end{array}$ \\
\hline Preoperative-one month postoperative & $<0.001$ & $<0.001$ \\
\hline Preoperative-three months postoperative & $<0.001$ & $<0.001$ \\
\hline Preoperative-six months postoperative & $<0.001$ & $<0.001$ \\
\hline $\begin{array}{l}\text { One month postoperative-three months } \\
\text { postoperative }\end{array}$ & 0.276 & $<0.001$ \\
\hline $\begin{array}{l}\text { One month postoperative-six months } \\
\text { postoperative }\end{array}$ & 0.825 & 1.000 \\
\hline $\begin{array}{l}\text { Three months postoperative-six months } \\
\text { postoperative }\end{array}$ & 1.000 & 0.600 \\
\hline
\end{tabular}

Abbreviations: ECD, endothelial cell density; FS-LASIK, femtosecond laser in situ keratomileusis; FS-SMILE, femtosecond small incision lenticular extraction.

A study was done by Munoz et al ${ }^{11}$ to assess the effects of femtosecond laser on the CED and percentage of HEX. They reported no statistically significant differences regarding mean ECD or HEX before and one year after FS-LASIK. In a study done by Tomita et $\mathrm{al}^{12}$ to compare two different femtosecond lasers used for flap creation during laserassisted in situ keratomileusis (LASIK) surgery on the corneal endothelium, there were no statistically significant differences in the corneal morphology between pre and post LASIK results in each group. The use of either femtosecond lasers for lamellar flap creation did not have an adverse effect on ECD and/or endothelial morphology. In a study done by Klingler et $\mathrm{al}^{13}$ to compare the ECD and the morphology between flap creation with a femtosecond laser and flap creation with a mechanical microkeratome five years after laser in situ keratomileusis (LASIK), there were no 
Table 7 P-value in a Pairwise Comparison of CV Between Time Points for Each Treatment Modality

\begin{tabular}{|c|c|c|}
\hline $\begin{array}{l}\text { A Pairwise Comparison at } \\
\text { Different Points of Time }\end{array}$ & $\begin{array}{l}\text { FS-LASIK } \\
(\mathrm{N}=40) \mathrm{P} \text {-value }\end{array}$ & $\begin{array}{l}\text { FS-SMILE } \\
(\mathrm{N}=40) \\
\text { P-value } \\
\text { value }\end{array}$ \\
\hline Preoperative-one month postoperative & $<0.001$ & $<0.001$ \\
\hline $\begin{array}{l}\text { Preoperative-three months } \\
\text { postoperative }\end{array}$ & $<0.001$ & $<0.001$ \\
\hline Preoperative-six months postoperative & $<0.001$ & $<0.001$ \\
\hline $\begin{array}{l}\text { One month postoperative } \\
\text { t-operative-three months post- } \\
\text { operative }\end{array}$ & 0.151 & 0.001 \\
\hline $\begin{array}{l}\text { One month postoperative-six months } \\
\text { postoperative }\end{array}$ & 0.002 & $<0.001$ \\
\hline $\begin{array}{l}\text { Three months postoperative-six } \\
\text { months postoperative }\end{array}$ & 0.004 & 0.487 \\
\hline
\end{tabular}

Abbreviations: CV, coefficient of variation of the cell size; FS-LASIK, femtosecond laser in situ keratomileusis; FS-SMILE, femtosecond small incision lenticular extraction.

Table 8 P-value in a Pairwise Comparison of HEX Between Time Points for Each Treatment Modality

\begin{tabular}{|l|l|l|}
\hline $\begin{array}{l}\text { A Pairwise Comparison at } \\
\text { Different Points of Time }\end{array}$ & $\begin{array}{l}\text { FS-LASIK } \\
(\mathbf{N}=\mathbf{4 0}) \text { P-value }\end{array}$ & $\begin{array}{l}\text { FS-SMILE } \\
(\mathbf{N}=\mathbf{4 0}) \text { P-value }\end{array}$ \\
\hline $\begin{array}{l}\text { Preoperative-one month } \\
\text { postoperative }\end{array}$ & $<0.001$ & $<0.001$ \\
$\begin{array}{l}\text { Preoperative-three months } \\
\text { postoperative }\end{array}$ & $<0.001$ & $<0.001$ \\
$\begin{array}{l}\text { Preoperative-six months } \\
\text { postoperative }\end{array}$ & $<0.001$ \\
$\begin{array}{l}\text { One month postoperative-three } \\
\text { months postoperative } \\
\text { One month postoperative-six } \\
\text { months postoperative } \\
\text { Three months postoperative-six } \\
\text { months postoperative }\end{array}$ & $<0.001$ & $<0.001$ \\
\hline
\end{tabular}

Abbreviations: HEX, hexagonality of the endothelial cells; FS-LASIK, femtosecond laser in situ keratomileusis; FS-SMILE, femtosecond small incision lenticular extraction.

differences in the ECD, CV, or the percentage of HEX between treatments at any examination. Five years after LASIK, the energy delivered to the cornea during flap creation with femtosecond laser did not affect the corneal endothelium when compared with flap creation with a mechanical microkeratome. In a study done by $\mathrm{Lu}$ et $\mathrm{al}^{14}$ to observe the ECD and morphology after FS-LASIK, one month after surgery, the ECD was $2815.34 \pm 297.07 / \mathrm{mm} 2$, which had a $2.64 \%$ decrease compared with preoperative ECD. Postoperatively, the ECD, HEX, and CV of the corneal endothelial cells did not change statistically. In our study, in the FS-LASIK group, we had preoperative ECD of $2946.5 \pm$

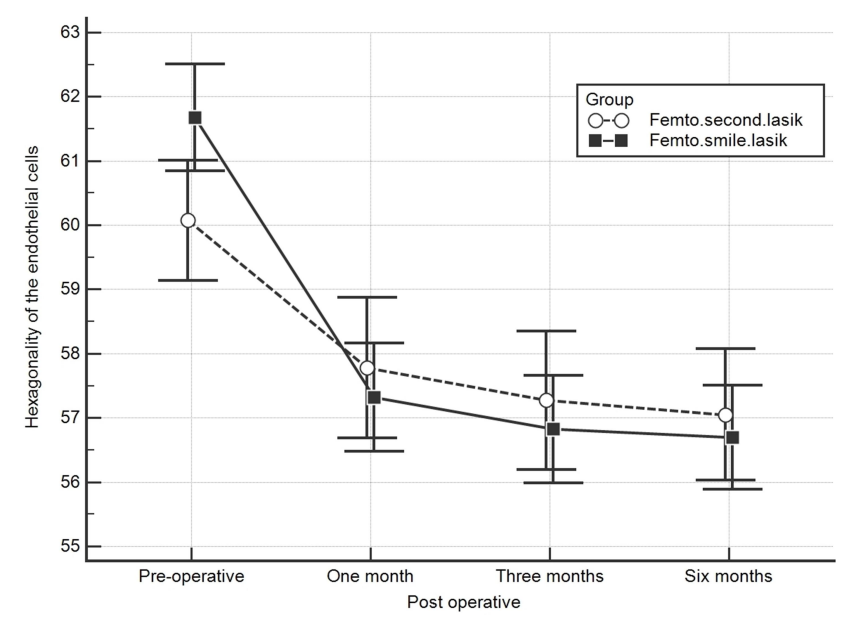

Figure 3 Showing the hexagonality of the endothelial cells in both treatment modalities over the different points of follow-up.

Abbreviations: FS-LASIK, femtosecond laser in situ keratomileusis; FS-SMILE, femtosecond small incision lenticular extraction.

$151.28 / \mathrm{mm} 2$, which turned to be $2909.13 \pm 147.43 / \mathrm{mm} 2$ after one month ( $-1,26 \%$ decrease), Tables 1 and 4.

Cabral et $\mathrm{al}^{15}$ studied the ECD and the $\mathrm{CV}$ in 30 eyes of 15 patients with myopia ranging from -3.25 to -10.00 $\mathrm{D}$ and astigmatism up to $-3.50 \mathrm{D}$ who were treated with FS-SMILE. The ECD and the CV were measured preoperatively and at one day and three months postoperatively. No significant changes were observed regarding $\mathrm{ECD}$ and $\mathrm{CV}$ at any visit point. No eyes developed corneal edema or other complications.

Wang et $\mathrm{al}^{16}$ assessed the effects of small incision lenticule extraction (SMILE) surgery on the corneal endothelium at one day, one week, and one month postoperatively on 47 eyes who received SMILE surgery. The corneal endothelium was analyzed. There were no significant changes in the ECD, $\mathrm{CV}$, HEX for one-month follow-up.

Zhang et $\mathrm{al}^{17}$ investigated the corneal endothelial changes one day, and one year after the SMILE procedure. They studied a total of 56 eyes of 30 patients with myopia ranging from -3.25 to $-8.25 \mathrm{D}$ and cylinder up to $-3.50 \mathrm{D}$ who were treated by SMILE. The ECD, CV, and HEX were measured preoperatively and at one day, and one year postoperatively. There were no significant changes in the ECD, CV, or HEX at any visit point and no vision-threatening complications occurred during the follow-up period.

Kamiya et $\mathrm{a}^{18}$ studied the endothelial cell loss, of refractive lenticule extraction with the use of a $500 \mathrm{kHz}$ femtosecond laser to correct myopia. The ECD was $2814 \pm 199$ cells/ $\mathrm{mm}^{2}$ preoperatively and $2762 \pm 213$ cells $/ \mathrm{mm}^{2}$ six months postoperatively, the change was not significant. In our study, 
we had preoperative ECD of $3037.88 \pm 160.81 / \mathrm{mm}^{2}$, and $2912.75 \pm 169.60 / \mathrm{mm}^{2}$ six months postoperatively, the change was significant (Tables 2 and 5). In both studies, no eyes developed any corneal complications during the followup period throughout the 6-month follow-up. Kamiya et $\mathrm{al}^{19}$ studied the clinical results of small incision lenticule extraction (SMILE) for the correction of myopia and myopic astigmatism for one year using a $500 \mathrm{kHz}$ femtosecond laser system. The corneal endothelial cell loss and the adverse events of the surgery had been assessed preoperatively, one week, and one, three, six, and twelve months postoperatively. No significant change in ECD occurred throughout the one-year follow-up period. The ECD changed from $2804 \pm 26$ cells $/ \mathrm{mm}^{2}$ preoperatively to $2743 \pm 308$ cells/ $\mathrm{mm}^{2}$ one year postoperatively. Most studies conducted in the literature were not comparative as they were only studying the effect of either the FS-LASIK or the FS- SMILE on the corneal endothelium.

In this study, although all the changes in ECD and morphology were statistically significant in both groups, and the FS-SMILE group was more statistically affected, there were no adverse clinical effects, no vision-threatening complications, or any other corneal complications in both groups throughout a six-month follow-up. The ECD, CV, and HEX being more affected in the FS-SMILE group may be due to the deeper penetration of the FS-laser in the corneal tissue during the FS-SMILE when compared to FS-LASIK.

The percentage endothelial cell loss in both groups may seem of little value (Table 5), but in some patients with compromised endothelium, this difference might be crucial. Also, one should consider that this loss might increase with time or with other factors such as trauma and surgery. Although SMILE induced minimal effects on corneal endothelial cells, further studies are required with a larger number of cases, longer duration of follow-ups, lower preoperative ECD, and deeper lenticule extraction to confirm the long-term effect of femtosecond laser use on the corneal endothelium.

We may consider that the results of this study are limited by the relatively low number of cases ( 80 eyes) and the relatively short follow-up period (6 months). Therefore, further longer-term studies on a larger number of patients are needed to investigate the effects of these two procedures on the corneal endothelium.

\section{Conclusion}

In this study, FS-LASIK and FS-SMILE were performed successfully to correct myopia and myopic astigmatism.
Although the endothelial cell density (ECD) and morphology were affected in both techniques, it was noticed statistically that the FS-SMILE had more impact on the ECD and morphology as a short term find. The effect of FS-SMILE on the endothelium may be explained by the deeper level of high energy applied. This, however, did not result in any harmful effect on the cornea and seemed to stop after a few weeks without causing any harm after the 6 month follow-up period.

\section{Acknowledgments}

The authors acknowledge the support of Dr. Mustafa HM, professor of Community and Public Health, Faculty of Medicine, Ain Shams University, for performing the statistics of this study.

\section{Disclosure}

The authors report no conflicts of interest for this work.

\section{References}

1. Pallikaris IG, Papatzanaki ME, Stathi EZ, Frenschock O, Georgiadis A. Laser in situ keratomileusis. Lasers Surg Med. 1990;10(5):463468.

2. Blum M, Kunert K, Gille A, Sekundo W. LASIK for myopia using the Zeiss VisuMax femtosecond laser and MEL 80 excimer laser. $J$ Refract Surg. 2009;25(4):350-356.

3. Reinstein DZ, Archer TJ, Gobbe M. Small incision lenticule extraction (SMILE) history, fundamentals of a new refractive surgery technique, and clinical outcomes. Eye Vis (Lond). 2014;1:3.

4. Sekundo W, Kunert KS, Blum M. Small incision corneal refractive surgery using the small incision lenticule extraction (SMILE) procedure for the correction of myopia and myopic astigmatism: results of a 6- month prospective study. Br J Ophthalmol. 2011;95:335-339.

5. Shah R, Shah S, Sengupta S. Results of small incision lenticule extraction: all-in-one femtosecond laser refractive surgery. $J$ Cataract Refract Surg. 2011;37:127-137.

6. Hjortdal JO, Vestergaard AH, Ivarsen A, Ragunathan S. Asp S: predictors for the outcome of small incision lenticule extraction for Myopia. J Refract Surg. 2012;28:865-871.

7. Denoyer A, Landman E, Trinh L, Faure JF, Auclin F, Baudouin C. Dry eye disease after refractive surgery: comparative outcomes of small incision lenticule extraction versus LASIK. Ophthalmology. 2015;122(4):669-676.

8. Sekundo W, Kunert K, Russmann C, et al. First efficacy and safety study of femtosecond lenticule extraction for the correction of myopia: six-month results. J Cataract Refract Surg. 2008;34(9):15131520.

9. Randleman JB, Dawson DG, Grossniklaus HE, McCarey BE, Edelhauser HF. Depth-dependent cohesive tensile strength in human donor corneas: implications for refractive surgery. J Refract Surg. 2008;24(1):S85-89.

10. Reinstein DZ, Archer TJ, Randleman JB. A mathematical model to compare the relative tensile strength of the cornea after PRK, LASIK, and small incision lenticule extraction. J Refract Surg. 2013;29 (7):454-460

11. Muñoz G, Albarrán-Diego C, Sakla HF, Ferrer-Blasco T, Javaloy J. Effects of LASIK on corneal endothelium using the $15-\mathrm{kHz}$ IntraLase femtosecond laser. J Refract Surg. 2011;27:672-677. 
12. Tomita M, Waring GO 4th, Watabe M. Analysis of corneal endothelial cell density and morphology after laser in situ keratomileusis using two types of femtosecond lasers. Clin Ophthalmol. 2012;6:1567-1572.

13. Klingler KN, McLaren JW, Bourne WM, Patel SV. Corneal endothelial cell changes 5 years after laser in situ keratomileusis: femtosecond laser versus mechanical microkeratome. J Cataract Refract Surg. 2012;38(12):2125-2130.

14. Lu XL, Yang FL, Bao YZ. Observation of corneal endothelial cells after femtosecond laser in situ keratomileusis. Guoji. Yanke Zazhi. Int Eye Sci. 2015;15(2):208-210.

15. Cabral J, Guzman-Iturbe FD, Navas A, Jimenez-Corona A, GraueHernandez EO, Ramirez-Miranda AJ. Effects of small incision lenticule extraction (SMILE) on corneal endothelial cells. Association for Research in Vision and Ophthalmology (ARVO) 2016 Annual Meeting. May 04, 2016
16. Wang DY, Liu ML, Chen YL, et al. Short term effects of small incision lenticule extraction surgery on corneal endothelium. Int $J$ Ophthalmol. 2016;9(4):536-539.

17. Zhang H, Wang Y, Xie S, Wu D, Wu W, Xu L. Short-term and longterm effects of small incision lenticule extraction (SMILE) on corneal endothelial cells. Cont Lens Anterior Eye. 2015;38(5):334-338.

18. Kamiya K, Igarashi A, Ishii R, Sato N, Nishimoto H, Shimizu K. Early clinical outcomes, including efficacy and endothelial cell loss, of refractive lenticule extraction using a $500 \mathrm{kHz}$ femtosecond laser to correct myopia. J Cataract Refract Surg. 2012;38(11):1996-2002.

19. Kamiya K, Shimizu K, Igarashi A, Kobashi H. Visual and refractive outcomes of small incision lenticule extraction for the correction of myopia: 1-year follow-up. BMJ Open. 2015;5(11):e008268.

\section{Publish your work in this journal}

Clinical Ophthalmology is an international, peer-reviewed journal covering all subspecialties within ophthalmology. Key topics include: Optometry; Visual science; Pharmacology and drug therapy in eye diseases; Basic Sciences; Primary and Secondary eye care; Patient Safety and Quality of Care Improvements. This journal is indexed on PubMed
Central and CAS, and is the official journal of The Society of Clinical Ophthalmology (SCO). The manuscript management system is completely online and includes a very quick and fair peer-review system, which is all easy to use. Visit http://www.dovepress.com/ testimonials.php to read real quotes from published authors. 